\title{
Phonon density of states of self-assembled isolated Fe-rich Fe-Pt alloy nanoclusters
}

\author{
B. Roldan Cuenya, ${ }^{1,2, *}$ Jason R. Croy, ${ }^{1}$ L. K. Ono, ${ }^{1}$ A. Naitabdi, ${ }^{1}$ H. Heinrich,,${ }^{1,3}$ W. Keune,,${ }^{4,5}$ J. Zhao, ${ }^{6}$ W. Sturhahn, ${ }^{6}$ \\ E. E. Alp, ${ }^{6}$ and M. $\mathrm{Hu}^{6}$ \\ ${ }^{1}$ Department of Physics, University of Central Florida, Orlando, Florida 32816, USA \\ ${ }^{2}$ Nanoscience Technology Center, University of Central Florida, Orlando, Florida 32816, USA \\ ${ }^{3}$ Advanced Materials Processing and Analysis Center, University of Central Florida, Orlando, Florida 32816, USA \\ ${ }^{4}$ Fachbereich Physik, Universität Duisburg-Essen, D-47048 Duisburg, Germany \\ ${ }^{5}$ Max-Planck-Institut für Mikrostrukturphysik, D-06120 Halle, Germany \\ ${ }^{6}$ Advanced Photon Source, Argonne National Laboratory, Argonne, Illinois 60439, USA
}

(Received 10 June 2009; published 16 September 2009)

\begin{abstract}
The Fe-projected phonon density of states (PDOS) of monolayer-thick films of self-assembled, size-selected, isolated ${ }^{57} \mathrm{Fe}_{1-\mathrm{x}} \mathrm{Pt}_{\mathrm{x}}$ alloy nanoclusters (NCs) (height: $\sim 2 \mathrm{~nm}$, diameter: $\sim 8 \mathrm{~nm}$ ) supported on flat $\mathrm{SiO}_{2} / \mathrm{Si}(111)$ substrates has been measured by nuclear resonant inelastic $\mathrm{x}$-ray scattering. The samples were characterized by atomic force microscopy (AFM), transmission electron microscopy, and x-ray photoelectron spectroscopy (XPS). Surface segregation of Pt and PtSi formation at the NC surface due to the samplepreparation process is inferred from the XPS data. As compared to the bulk, pronounced modifications of the PDOS beyond the bulk cut-off energy are observed in bcc ${ }^{57} \mathrm{Fe}_{0.8} \mathrm{Pt}_{0.2}$ (core)/PtSi(shell) NCs. By contrast, the PDOS of fcc ${ }^{57} \mathrm{Fe}_{0.75} \mathrm{Pt}_{0.25}$ (core)/PtSi(shell) NCs retains features of bulk ordered $\mathrm{Fe}_{3} \mathrm{Pt}$ Invar alloys (presumably due to a thicker PtSi shell), in particular, the transverse-acoustic [110] $\mathrm{TA}_{1}$ mode near 9 meV. Apparently, this mode is not affected by size effects. The existence of the [110] $\mathrm{TA}_{1}$ phonon mode is a prerequisite for the persistence of Invar-related effects in $\mathrm{Fe}_{3} \mathrm{Pt} \mathrm{NCs}$. Important thermodynamic properties of the NCs are derived, such as the vibrational entropy per atom.
\end{abstract}

DOI: 10.1103/PhysRevB.80.125412

PACS number(s): 63.22.Kn, 63.20.D-, 65.80.+n

\section{INTRODUCTION}

The phonon density of states (PDOS), $g(E)$, describes the vibrational dynamics of atoms in solids and is a fundamental property that affects phase stability and phase transitions in alloys. 1,2 An important type of phase transition is the diffusionless (displacive) austenite (fcc)-to-martensite (bct) (or reverse) transformation in Fe-based Invar alloys, e.g., in $\mathrm{Fe}_{65} \mathrm{Ni}_{35}$ or $\mathrm{Fe}_{3} \mathrm{Pt}$ alloys. ${ }^{3,4}$ Invar alloys are ferromagnetic and of basic and technological significance owing to their remarkable properties, such as giant magnetovolume effect and small thermal expansion. ${ }^{3,4}$ An important characteristic of Invar alloys, e.g., of $\mathrm{L1}_{2}-\left(\mathrm{Cu}_{3} \mathrm{Au}\right)$ ordered $\mathrm{Fe}_{3} \mathrm{Pt}$, is the pronounced softening of the low-energy (low-E) transverseacoustic [110] $\mathrm{TA}_{1}$ phonon mode (shear mode) upon cooling below the Curie temperature, ${ }^{5-11}$ leading to elastic anomalies and martensitic transformation at low temperature. ${ }^{3}$ These effects have been discussed in terms of enhanced electronphonon interactions ${ }^{5,6}$ due to the high electronic DOS of $d$ electrons near the Fermi energy in Invar alloys. ${ }^{12-14}$ Thus, detailed knowledge of the phonon spectrum is essential for the understanding of Invar-related properties. ${ }^{15}$ Recently, $\mathrm{Fe}_{3} \mathrm{Pt}$ nanowire arrays (with Invar composition) have been fabricated. ${ }^{16,17}$ The fundamental question arises whether the Invar effect and the related martensitic transition are suppressed in $\mathrm{Fe}_{3} \mathrm{Pt}$ (or other Invar-type) nanostructures due to finite-size effects. In Fe-Ni nanoclusters (NCs), the martensitic transition has been investigated experimentally ${ }^{18}$ and the absence of structural instability below a certain NC size has been observed. According to theory ${ }^{19,20}$ the transformation temperature upon heating scales with, and is inversely proportional to, NC diameter. This is contrary to the trans- formation upon cooling, which appears to be suppressed due to the high metastability of the fcc phase and the lack of nucleation sites. Recent molecular dynamics simulations for elemental Fe nanowires predict that the martensitic transition temperature is inversely proportional to the wire diameter during heating and depends linearly on applied axial tensile stress. ${ }^{21}$ An essential prerequisite for the occurrence of the martensitic transformation in Invar alloy NCs is the existence of the [110] $\mathrm{TA}_{1}$ phonon mode, since softening of this mode is the origin of this instability in the bulk..$^{3,5-8,15}$ Therefore, a fundamental question is whether the [110] $\mathrm{TA}_{1}$ mode still exists in Invar-alloy NCs. This is not clear, since in isolated metallic NCs, due to their large surface-to-volume ratio, distinct modifications of the phonon spectrum as compared to the bulk PDOS have been predicted in Refs. 22-28 and recently observed on isolated supported $\mathrm{Fe} \mathrm{NCs}^{28}$ Therefore, the experimental determination of the PDOS in Invar NCs is of fundamental importance.

This work presents an experimental study of the partial PDOS of isolated, monodispersed, bimetallic nanoclusters. Fe-projected PDOS curves, $g(E)$, were obtained from ${ }^{57} \mathrm{Fe}$ nuclear resonant inelastic X-ray scattering (NRIXS). As compared to the bulk case, we observe strong modifications of $g(E)$ of bcc ${ }^{57} \mathrm{Fe}_{0.8} \mathrm{Pt}_{0.2}$ alloy NCs extending beyond the bulk cut-off energy. By contrast, such modifications are not found in fcc ${ }^{57} \mathrm{Fe}_{0.75} \mathrm{Pt}_{0.25}$ alloy NCs with Invar composition. Here, characteristic features of the PDOS of bulk $\mathrm{L}_{2}$-ordered In$\operatorname{var}\left(\mathrm{Fe}_{3} \mathrm{Pt}\right)$ alloys appear in $g(E)$ of the Invar alloy $\mathrm{NCs}$, including a shoulder near $\sim 9 \mathrm{meV}$ which can be attributed to the $[110] \mathrm{TA}_{1}$ mode of the $\mathrm{Fe}_{3} \mathrm{Pt}$ Invar alloy. The existence of this phonon mode is a necessary condition for the persistence of Invar-related effects in low-dimensional systems. 
Moreover, important thermodynamic properties of the NCs have been derived from the PDOS.

\section{EXPERIMENTAL DETAILS AND SAMPLE CHARACTERIZATION}

Monolayer-thick films of size-selected, isolated ${ }^{57} \mathrm{Fe}_{1-\mathrm{x}} \mathrm{Pt}_{\mathrm{x}}$ NCs uniformly spaced over large surface areas were prepared by micelle encapsulation ${ }^{28-31}$ of ${ }^{57} \mathrm{FeCl}_{3}$ and $\mathrm{H}_{2} \mathrm{PtCl}_{6}$ salts in PS(27700)-P2VP(4300) diblock copolymers. Samples of bimetallic clusters with two different nominal compositions of ${ }^{57} \mathrm{Fe}_{0.8} \mathrm{Pt}_{0.2}$ (sample 1) and ${ }^{57} \mathrm{Fe}_{0.3} \mathrm{Pt}_{0.7}$ (sample 2) were obtained by tuning the relative concentration ratio of the two metal salts.

NRIXS on the $\mathrm{SiO}_{2} / \mathrm{Si}(111)$ supported ${ }^{57} \mathrm{Fe}$-Pt NCs was performed at RT in air at beamlines 3-ID and HP-CAT16 of the Advanced Photon Source (Argonne) by tuning the synchrotron beam energy around the resonant energy of 14.4125 $\mathrm{keV}$ of the ${ }^{57} \mathrm{Fe}$ nucleus with an energy resolution of 2.3 $\mathrm{meV}(1.0 \mathrm{meV})$ for sample 1 (sample 2). The NRIXS method and the data evaluation for extracting $g(E)$ are described in detail elsewhere. ${ }^{32-36}$

Figure 1 shows atomic force microscopy (AFM) images from (a) sample 1 (nominal ${ }^{57} \mathrm{Fe}_{0.8} \mathrm{Pt}_{0.2}$ ) and (b) sample 2 (nominal ${ }^{57} \mathrm{Fe}_{0.3} \mathrm{Pt}_{0.7}$ ) containing NCs deposited on $\mathrm{SiO}_{2} / \mathrm{Si}(111)$. The average $\mathrm{NC}$ height before $\mathrm{Ar}^{+}$etching for these samples is $2.1 \pm 0.4 \mathrm{~nm}$. The etching did not result in distortions of the NC's spatial arrangement. It did, however, provide an ultrathin $\mathrm{Si}$ coating due to sputtering of $\mathrm{Si}$ atoms from the $\mathrm{Si}(111)$ substrate that prevented the NCs from oxidation upon air exposure, as evidenced by our cross-sectional transmission electron microscopy (TEM) [Fig. 1(c)] and $\mathrm{x}$-ray photoelectron spectroscopy (XPS) data (see below).

High-resolution-TEM (HR-TEM) images from samples 1 and 2 (NCs deposited on $\mathrm{C}$-coated $\mathrm{Cu}$ grids) are shown in Figs. 1(d) and 1(e), respectively. Single-grain NCs were observed in the case of sample 1, while multifaceted grains were detected in sample 2. The resolution of our TEM was not sufficient to detect a shell around the NC core. From these images, the typical cluster diameters are $\sim 8.2 \mathrm{~nm}$. According to our TEM and AFM data the aspect ratio (diameter/height) of our NCs is $\sim 4$. From the fast Fourier transform analysis of the TEM images in Figs. 1(d) and 1(e), a lattice parameter of $a=0.309 \pm 0.007 \mathrm{~nm}(0.379 \pm 0.007$ $\mathrm{nm}$ ) was determined for sample 1 (sample 2), assuming the bcc (fcc) phase. Our NRIXS results (see below) support the bcc (fcc) structure for sample 1 (sample 2). As a reference, the lattice parameters of bulk alloys with composition $\mathrm{Fe}_{0.8} \mathrm{Pt}_{0.2}$ (bcc) and $\mathrm{Fe}_{0.75} \mathrm{Pt}_{0.25}$ (fcc, $\mathrm{Fe}_{3} \mathrm{Pt}$ ) are given by $0.297 \mathrm{~nm}$ (extrapolated from data in Ref. 37) and 0.375 $\mathrm{nm},{ }^{38}$ respectively. Comparison indicates that the NCs in sample 1 are close to bcc $\mathrm{Fe}_{0.8} \mathrm{Pt}_{0.2}$, i.e., close to the nominal composition, while the NCs in sample 2 are close to fcc $\mathrm{Fe}_{0.75} \mathrm{Pt}_{0.25}$, which differs significantly from the nominal cluster composition of $\mathrm{Fe}_{03} \mathrm{Pt}_{07}$. As will be discussed later, this is attributed to the segregation of $\mathrm{Pt}$ to the NC surface leaving an Fe-rich core.

Figure 2 displays XPS spectra from the (a) Fe $2 p$ and (b) Pt $4 f$ core-level regions of NCs, in sample $2[(\mathrm{i})$ and (ii)] and
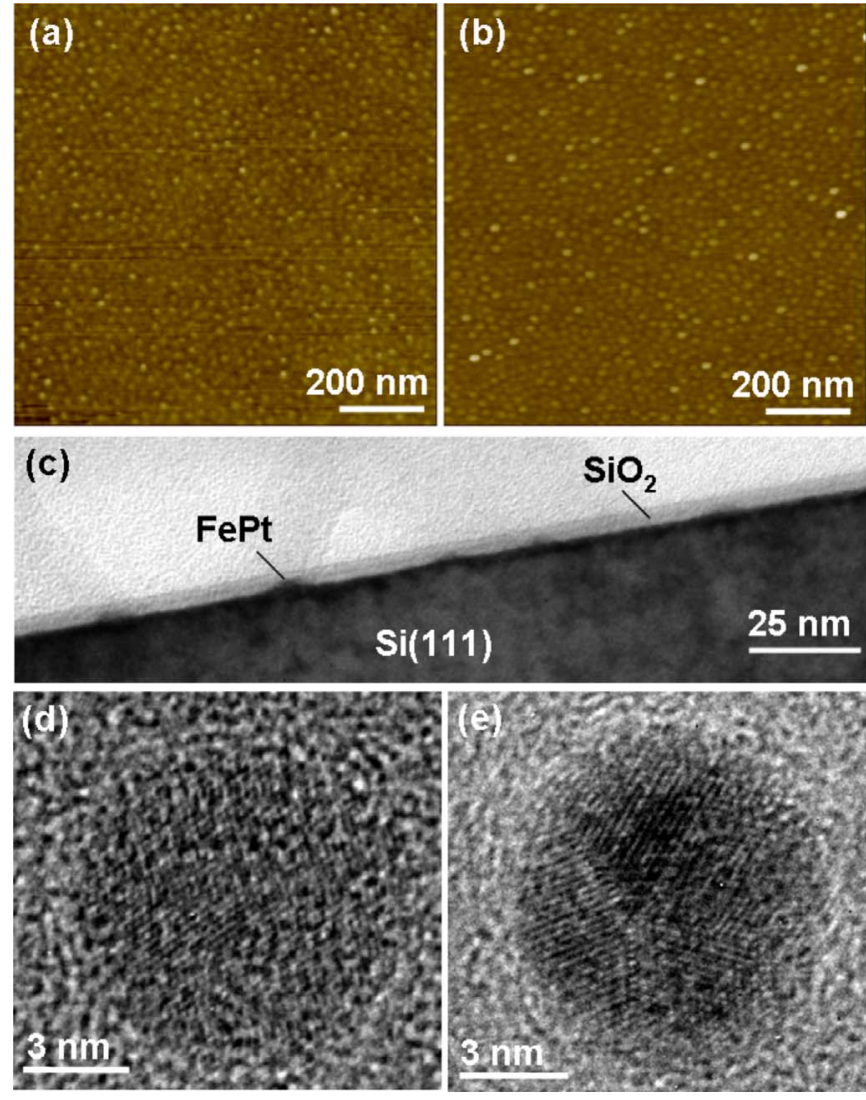

FIG. 1. (Color online) AFM and HR-TEM images of sample 1 [(a) and (d)] and sample 2 [(b) and (e)], with Fe-Pt alloy NCs synthesized as described in the text. (c) Cross-sectional TEM image of nanoclusters similar to those in sample 2, but synthesized using PS(81000)-PVP(14200) and deposited on $\mathrm{SiO}_{2} / \mathrm{Si}(111)$. All images were taken after polymer removal by annealing in UHV at $500{ }^{\circ} \mathrm{C}$ and subsequent $\mathrm{Ar}^{+}$-sputter etching $(0.5 \mathrm{keV}, 20 \mathrm{~min})$ at room temperature.

sample 1 [(iii) and (iv)], deposited on $\mathrm{SiO}_{2} / \mathrm{Si}(111) . \mathrm{Ar}^{+}$ etching resulted in an ultrathin Si coating on the samples that largely protected the $\mathrm{NCs}$ against oxidation, since no $\mathrm{Fe}^{3+}$ signal (e.g., $\mathrm{Fe}^{3+} 2 p_{3 / 2}$ in $\mathrm{Fe}_{2} \mathrm{O}_{3}$ : at $711 \mathrm{eV}$ ) ${ }^{39}$ was detected on these samples by XPS after air exposure. The binding energy (BE) of $\mathrm{Fe}$ in these bimetallic clusters $\left(2 p_{3 / 2}, 707.3\right.$ $\mathrm{eV})$ is in agreement with that of metallic iron (707.0-707.3 $\mathrm{eV})^{39}$ or $\mathrm{Fe}_{0.48} \mathrm{Pt}_{0.52}$ films $(707.5 \mathrm{eV}){ }^{40}$ By contrast, a very large $\mathrm{BE}$ was measured for $\mathrm{Pt}$ in our $\mathrm{NC}$ samples $\left(4 f_{7 / 2}\right.$, 73.0-73.1 eV) before and after air exposure. These BEs are up to $+2.0 \mathrm{eV}$ larger than for bulk $\mathrm{Pt}^{0}\left(4 f_{7 / 2}, 71.1 \mathrm{eV}\right)^{39}$ and are attributed to the formation of PtSi $\left(4 f_{7 / 2}, 73 \mathrm{eV}\right) .^{41}$ Our annealing treatment in vacuum (at $500{ }^{\circ} \mathrm{C}$ ) resulted in preferential segregation of $\mathrm{Pt}$ to the NC surface, which readily reacted with Si during the subsequent $\mathrm{Ar}^{+}$-etching procedure. This trend for Pt segregation is in agreement with calculations and experimental results on Fe-Pt systems. ${ }^{42-44} \mathrm{We}$ infer that our NCs carry a thin PtSi shell, which is much thinner for the NCs in sample 1 because of its weaker Pt- $4 f$ signal (20\% Pt content) as compared to sample $2(70 \% \mathrm{Pt}$ content), and because the nominal and actual compositions of the NC core $\left(\mathrm{Fe}_{0.8} \mathrm{Pt}_{0.2}\right)$ agree fairly well with each other, contrary to the case of sample 2 . We expect that the observed 

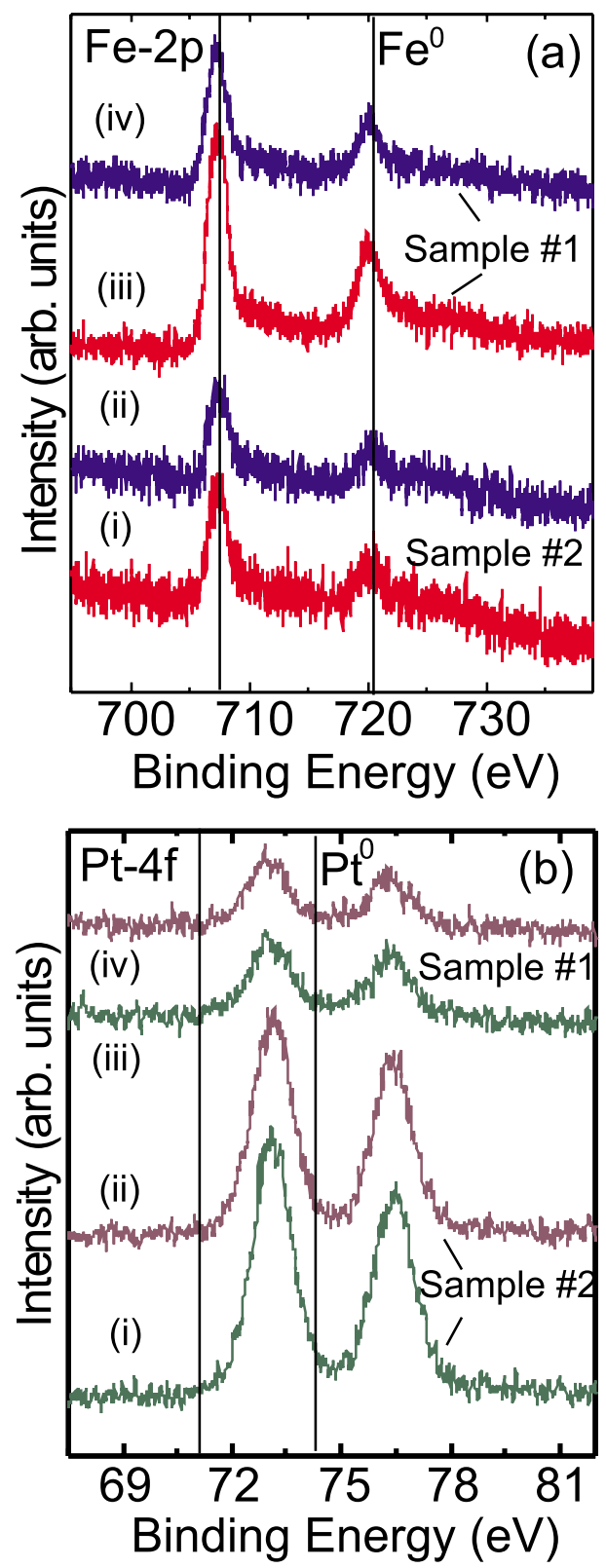

FIG. 2. (Color online) XPS spectra (Al $K \alpha=1486.6 \mathrm{eV})$ of the (a) $\mathrm{Fe}-2 p$ and (b) Pt- $4 f$ core levels of similarly sized Fe-Pt alloy nanoclusters in samples 1 and 2 deposited on $\mathrm{SiO}_{2} / \mathrm{Si}(111)$. The spectra were measured after polymer removal by annealing in UHV at $500{ }^{\circ} \mathrm{C}$ followed by $\mathrm{Ar}^{+}$-sputter-etch [(i) and (iii)], and after subsequent air exposure for 4 days [(ii) and (iv)].

Pt surface segregation and PtSi shell formation will influence the PDOS of the NCs (see below).

\section{NRIXS RESULTS AND DISCUSSION}

Figure 3 displays NRIXS spectra (raw data) of (a) sample 1 (NC core: bcc ${ }^{57} \mathrm{Fe}_{0.8} \mathrm{Pt}_{0.2}$ ) and (b) sample 2 (NC core: fcc $\left.{ }^{57} \mathrm{Fe}_{0.75} \mathrm{Pt}_{0.25}\right)$. The main features of these spectra are an intense elastic peak at $E=0 \mathrm{meV}$ (Mössbauer or zero-phonon line) and side bands at higher and lower excitation energies $E$ corresponding to phonon-assisted excitation of the nuclear

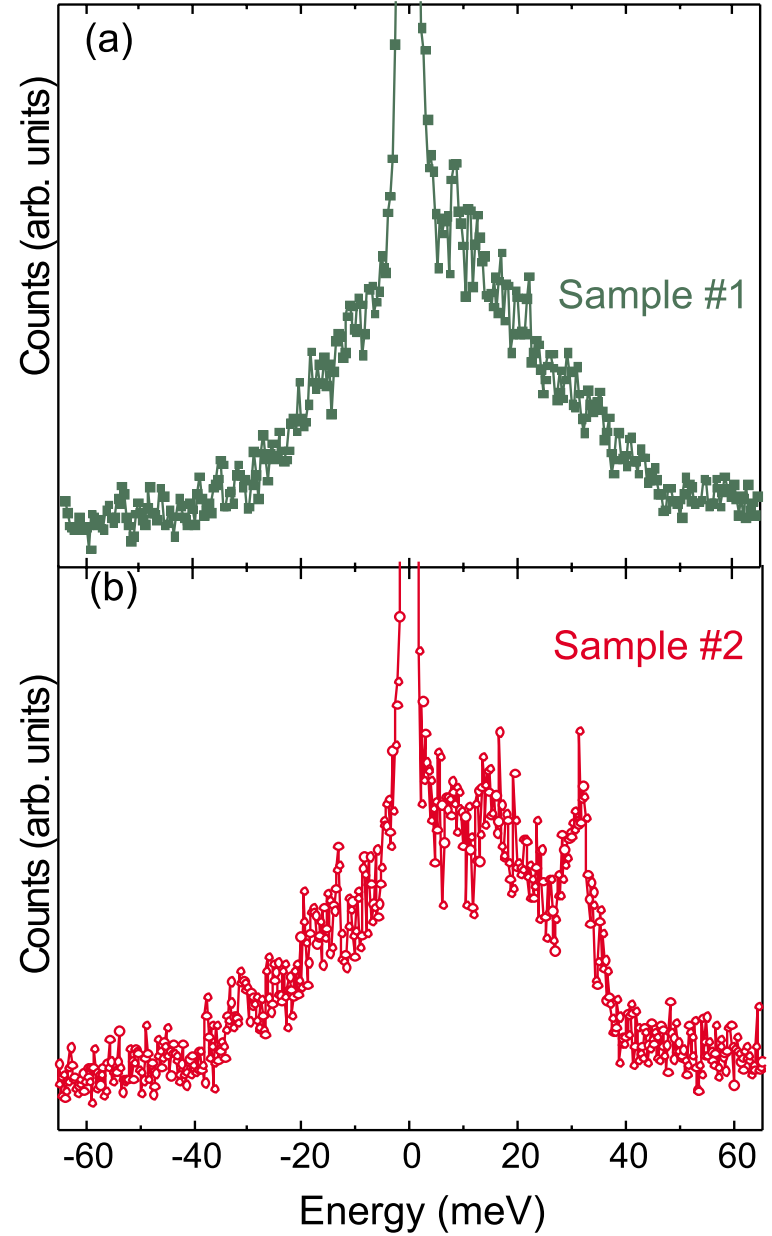

FIG. 3. (Color online) Experimental NRIXS spectra (raw data) taken at RT from Fe-Pt alloy NCs supported on $\mathrm{SiO}_{2} / \mathrm{Si}(111)$ : (a) sample 1 (bcc alloy) and (b) sample 2 (fcc alloy).

resonance by photons via phonon creation $(E>0)$ and annihilation $(E<0)$. A broad and nearly structureless phonon excitation spectrum is observed for sample 1 [Fig. 3(a)], while sharper phonon features near $\sim 31$ and $\sim 13 \mathrm{meV}$ and a cutoff near $40 \mathrm{meV}$ are noticed for sample 2, Fig. 3(b).

Figure 4(a) presents the Fe-projected (partial) PDOS, $g(E)$, of sample 1 (bcc ${ }^{57} \mathrm{Fe}_{0.8} \mathrm{Pt}_{0.2}$ ) (full squares) and of a reference bulk bcc ${ }^{57} \mathrm{Fe}$ foil (full-drawn line), obtained from measured data. Also shown is the PDOS of a reference NC sample (reproduced from Ref. 28, full circles) containing similarly sized, isolated, elemental bcc ${ }^{57} \mathrm{Fe} \mathrm{NCs}$ (of $\sim 2.3 \mathrm{~nm}$ average AFM height), subjected to an identical preparation technique and carrying an Fe-oxide shell, ${ }^{28}$ sample 3. Clear differences between $g(E)$ of sample 1 and bulk bcc Fe are observed: (i) the strong suppression of the longitudinal acoustic (LA) phonon peak at $\sim 36 \mathrm{meV}$ and of the transverse acoustic (TA) modes near $\sim 27$ and $\sim 22 \mathrm{meV}$, an effect that may be attributed to phonon damping due to confinement. ${ }^{45,46}$ However, a residue of the 36 $\mathrm{meV}$ phonon peak is visible in the $g(E)$ of sample 1 , which proves the existence of the bcc structure in the ${ }^{57} \mathrm{Fe}_{0.8} \mathrm{Pt}_{0.2}$ $\mathrm{NCs}$, in agreement with our TEM results. (ii) The enhancement of $g(E)$ at low and high energies, where excitations extend beyond the cut-off energy of $\sim 40 \mathrm{meV}$ of bulk bcc 


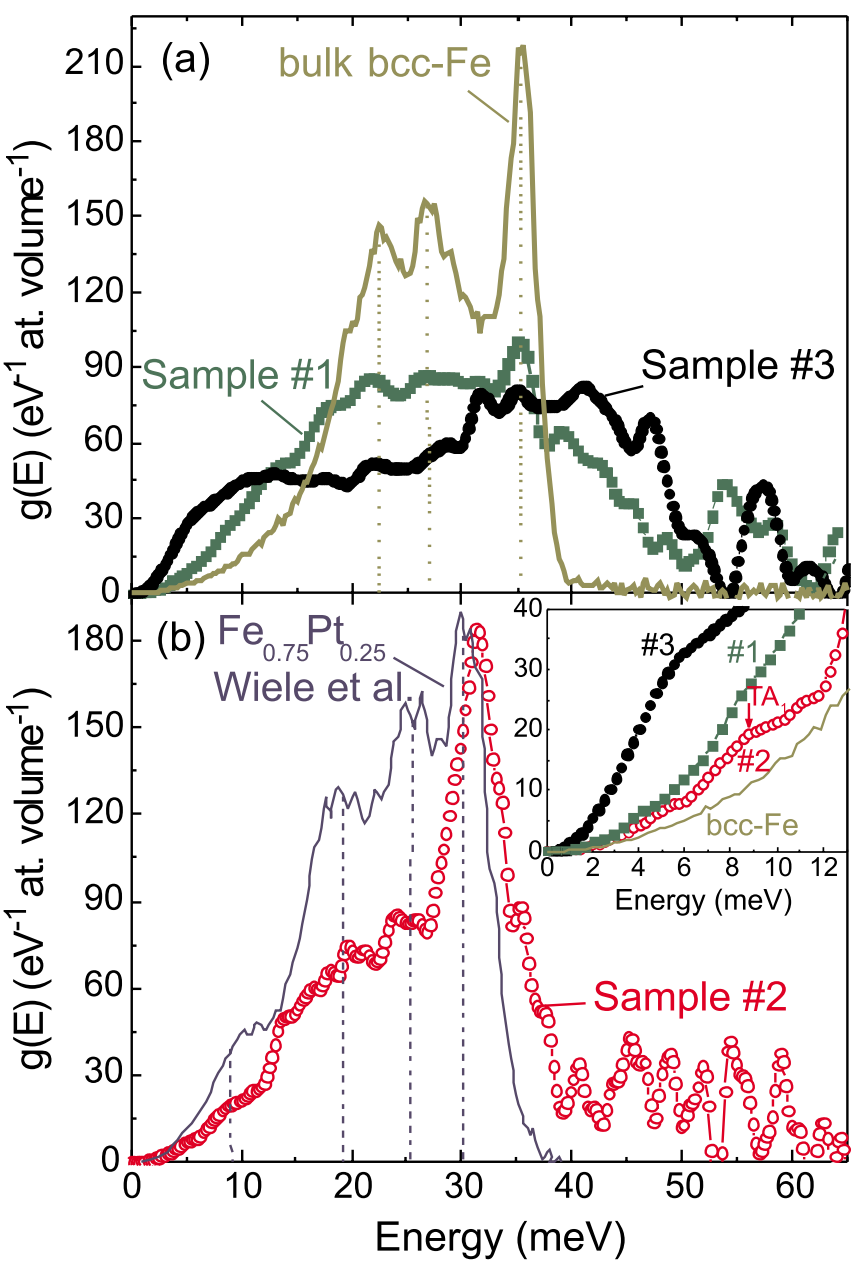

FIG. 4. (Color online) PDOS, $g(E)$, of Fe-Pt NCs, obtained from the data in Fig. 3: (a) sample 1 (bcc ${ }^{57} \mathrm{Fe}_{0.8} \mathrm{Pt}_{0.2}$ ) (full squares). Also shown: measured $g(E)$ of bulk bcc ${ }^{57} \mathrm{Fe}$ (full-drawn curve) and of elemental bcc ${ }^{57} \mathrm{Fe} \mathrm{NCs} \mathrm{(sample} \mathrm{3)} \mathrm{from} \mathrm{Ref.} 28$ (full circles). (b) sample 2 (fcc ${ }^{57} \mathrm{Fe}_{0.75} \mathrm{Pt}_{0.25}$ ) (open circles). Also shown: measured $g(E)$ of a bulk $\mathrm{L1}_{2}$-ordered $\mathrm{Fe}_{0.75} \mathrm{Pt}_{0.25}$ Invar alloy (Refs. 10 and 11) (full-drawn curve). Inset in (b): low-energy part of $g(E)$.

Fe. This effect is less pronounced than for sample $3 .^{28}$ According to theory, the low-E enhancement is attributed to low-coordinated vibrational surface states, ${ }^{22-28}$ while the high-energy (high-E) enhancement has been predicted to depend on compressive stress due to enhanced capillary forces in the $\mathrm{NCs}^{22,47}$ or to shrinkage of near-neighbor atomic bond lengths of specific atoms relative to bulk..$^{23-27}$ In fact, it was observed experimentally in isolated ${ }^{57} \mathrm{Fe}$ NCs that the lowand high-E enhancements in $g(E)$ depend on the thickness and type of the Fe-containing shell around the ${ }^{57} \mathrm{Fe} \mathrm{NCs}$ [i.e., $\mathrm{Fe}_{2} \mathrm{O}_{3}$ or $\mathrm{Fe}_{3} \mathrm{C}$ (Ref. 28)]. Therefore, the remarkable decrease in the low-E and high-E regions of the PDOS of sample 1, as compared to that of sample 3 [Fig. 4(a)], can be attributed to the different shell structures ( $\mathrm{PtSi}$ versus ${ }^{57} \mathrm{Fe}_{2} \mathrm{O}_{3}$ ). Since we measure the ${ }^{57} \mathrm{Fe}$-projected PDOS, the presence of $\mathrm{Pt}$ and $\mathrm{Si}$ atoms (and the decrease in the number of ${ }^{57} \mathrm{Fe}$ atoms) at the NC surface of our sample 1 is expected to reduce the low-E part of $g(E)$ as compared to pure ${ }^{57} \mathrm{Fe}$ NCs.
The striking features of the Fe-projected PDOS of sample 2 (fcc ${ }^{57} \mathrm{Fe}_{0.75} \mathrm{Pt}_{0.25}$ ) (open circles) are a strong and dominant peak at $\sim 31 \mathrm{meV}$ and relatively weak PDOS in the medium- and low-E regimes of $g(E)$, with weak bands near $\sim 20$ and $\sim 25 \mathrm{meV}$, Fig. 4(b). The $\sim 31 \mathrm{meV}$ peak lies at significantly lower energy than the main $36 \mathrm{meV}$ peak of bulk bcc Fe, Fig. 4(a). The cut-off energy of sample 2 is at $\sim 40 \mathrm{meV}$, as is also revealed by the NRIXS raw data, Fig. $3(\mathrm{~b}){ }^{48}$

For comparison, we have reproduced in Fig. 4(b) (fulldrawn line) the $g(E)$ curve of $\mathrm{L1}_{2}$-ordered bulk $\mathrm{Fe}_{0.75} \mathrm{Pt}_{0.25}$ Invar alloy (with a long-range order parameter $S=0.8$ ) measured also by NRIXS by Wiele et al. ${ }^{10,11} \mathrm{~A}$ comparison of these two $g(E)$ curves reveals distinct differences, but also similarities: (i) both $g(E)$ curves span roughly the same energy range; (ii) the strong PDOS peak at $\sim 31 \mathrm{meV}$ in sample 2 almost coincides with the most intense peak in $g(E)$ at $\sim 30 \mathrm{meV}$ (optical phonon modes ${ }^{5,6}$ ) in the bulk Invar sample; (iii) the weak peaks near $\sim 20$ and $\sim 25 \mathrm{meV}$ for sample 2 coincide with phonon bands (other optical phonons ${ }^{5,6}$ ) at analogous positions in the bulk Invar sample; however, these phonon bands are considerably reduced in their $g(E)$ intensity (by about 50\%) in the NCs of sample 2 as compared to $g(E)$ of the bulk Invar alloy; (iv) a small blueshift of the cut-off energy from $\sim 38 \mathrm{meV}$ in the bulk Invar sample to $\sim 40 \mathrm{meV}$ in sample 2 exists; (v) a shoulder at $\sim 9 \mathrm{meV}$ is visible in the $g(E)$ of both samples, although $g(E)$ at the shoulder of sample 2 is reduced (by $\sim 50 \%$ ) relative to that of the bulk Invar sample [Fig. 4(b) and insert]. The energy of this shoulder $(\sim 9 \mathrm{meV})$ agrees well with that of the [110] $\mathrm{TA}_{1}$ mode (at the Brillouin zone boundary) in bulk ordered $\mathrm{Fe}_{3} \mathrm{Pt}$ at RT. ${ }^{5-11}$ This can be seen in the inelastic neutron scattering (INS) results by Noda and Endoh. ${ }^{6}$ In Fig. 1 (panel for $\Sigma_{4}$ ) of Ref. 6, the [110] TA dispersion curve of bulk ordered $\mathrm{Fe}_{3} \mathrm{Pt}$ Invar alloy at $295 \mathrm{~K}$ can be observed to merge horizontally at the zone boundary (at a reduced wave vector $\xi[110]=0.5$ ) at a phonon energy of $\sim 9 \mathrm{meV}$. This implies zero group velocity and enhanced $g(E)$ at that energy. Similar features (and, moreover, the mode softening upon cooling) can be seen in the [110] $\mathrm{TA}_{1}$ disperson curve of $\mathrm{L}_{2}$-ordered $\mathrm{Fe}_{72} \mathrm{Pt}_{28}$ Invar alloy, obtained by Kästner $e t a l .{ }^{8}$ from INS (see Fig. 1 of Ref. 8). Wiele $e t$ $a l .{ }^{10}$ and Wiele, ${ }^{11}$ in their NRIXS work, identified the shoulder near $9 \mathrm{meV}$ in $g(E)$ of bulk ordered Fe-Pt Invar alloys with the [110] $\mathrm{TA}_{1}$ mode and, in fact, observed a redshift (phonon softening) of this mode upon decreasing the temperature, in qualitative agreement with the INS results. ${ }^{6,8}$ Therefore, by analogy with the literature reports just described, we attribute the $g(E)$ shoulder at $\sim 9 \mathrm{meV}$, observed in our Fig. 4(b) for sample 2, to the [110] $\mathrm{TA}_{1}$ phonon mode responsible for the soft-mode behavior in bulk $\mathrm{Fe}_{3} \mathrm{Pt}$ Invar alloys and for the martensitic transition at low $T^{3,7-11}$

The appearance of the [110] $\mathrm{TA}_{1}$ phonon mode in $g(E)$ of sample 2 unambiguously proves that $\mathrm{Pt}$ atoms are dissolved in the fcc Fe lattice of the core of these NCs, and that the average alloy composition in the core is on the Fe-rich side, in agreement with our TEM results. This follows from the fact that at the Brillouin zone boundary of the [110] $\mathrm{TA}_{1}$ phonon mode only $\mathrm{Fe}$ atoms vibrate in a rigid cubic lattice of heavy $\mathrm{Pt}$ atoms $\left[\mathrm{M}_{2}\right.$ and $\mathrm{M}_{4}$ modes in ordered $\mathrm{Fe}_{3} \mathrm{Pt}$ (Refs. 
TABLE I. Thermodynamic parameters derived from NRIXS measurements.

\begin{tabular}{lcccc}
\hline \hline Sample & $\begin{array}{c}\text { Lamb-Mössbauer } \\
\text { factor }\end{array}$ & $\begin{array}{c}\text { Kinetic energy } \\
(\mathrm{meV} / \text { atom })\end{array}$ & $\begin{array}{c}\text { Vibrational entropy } \\
\left(k_{\mathrm{B}} / \text { atom }\right)\end{array}$ & $\begin{array}{c}\text { Vibrational specific heat } \\
\left(k_{\mathrm{B}} / \text { atom }\right)\end{array}$ \\
\hline $\mathrm{Fe}_{0.8} \mathrm{Pt}_{0.2} \mathrm{NCs}$ (bcc), sample 1 & $0.742(4)$ & $43.8(6)$ & $3.00(6)$ & $2.63(8)$ \\
$\mathrm{Fe}_{0.75} \mathrm{Pt}_{0.25} \mathrm{NCs}$ (fcc), sample 2 & $0.773(4)$ & $44.1(8)$ & $2.91(6)$ & $2.61(9)$ \\
$\mathrm{Fe} \mathrm{NCs} \mathrm{(bcc),} \mathrm{sample} \mathrm{3} \mathrm{(Ref.} \mathrm{28)}$ & $0.612(3)$ & $45.0(9)$ & $3.17(2)$ & $2.6(1)$ \\
$\mathrm{Fe} \mathrm{Nanocrystalline} \mathrm{(Ref.} \mathrm{45)}$ & $0.755(1)$ & $43.2(1)$ & & $2.68(2)$ \\
$\mathrm{Fe} \mathrm{NCs} \mathrm{(fcc)} \mathrm{in} \mathrm{Cu} \mathrm{(Ref.} \mathrm{52)}$ & $0.734(4)$ & & $3.133(9)$ & $2.723(9)$ \\
bcc Fe (bulk) (Ref. 53) & $0.7951(6)$ & $42.54(6)$ & \\
\hline \hline
\end{tabular}

5-8)]. Also important in this context is the observation by Fultz et al. ${ }^{49}$ that on the Pt-rich alloy side, $\mathrm{L1}_{2}$-ordered bulk $\mathrm{FePt}_{3}$ alloys exhibit a dominant sharp peak (optical phonons) in $g(E)$ at $25 \mathrm{meV}$, i.e., at significantly lower energy than our 31 meV peak, mainly caused by the higher average mass of $\mathrm{FePt}_{3}$ as compared to $\mathrm{Fe}_{3} \mathrm{Pt}$. Further, no significant feature of the $\mathrm{TA}_{1}$ mode near $\sim 7-9 \mathrm{meV}$ is observed in $g(E)$ of Pt-rich $\mathrm{L}_{2}$-ordered bulk FePt $3 .{ }^{49}$ From these considerations and from observations (i)-(iii) and (v) above, we conclude that the core of the alloy NCs in our sample 2 is close to the $\mathrm{Fe}_{3} \mathrm{Pt}$ Invar composition and is highly $\mathrm{L}_{2}$ ordered due to the relatively high annealing temperature of $500{ }^{\circ} \mathrm{C}$ under UHV conditions. Since the presence of the [110] $\mathrm{TA}_{1}$ phonon mode is an intrinsic property of bulk Fe-based ordered Invar alloys, ${ }^{5-11}$ the existence of this mode observed in our ordered $\mathrm{Fe}_{0.75} \mathrm{Pt}_{0.25}$ alloy $\mathrm{NCs}$ is a prerequisite for the existence of intrinsic Invar related properties of these NCs. Therefore, the observation of the [110] $\mathrm{TA}_{1}$ mode provides strong indirect evidence for the persistence of Invar-related properties in $\mathrm{Fe}_{3} \mathrm{Pt} \mathrm{NCs}$.

The remarkable reduction in the $g(E)$ intensity observed in the $\sim 20$ and $\sim 25 \mathrm{meV}$ (optical) phonon bands of the NCs [item (iii) above and Fig. 4(b)] may be due to one or more of the following reasons: (a) higher $\mathrm{L}_{2}$ ordering in the NCs than in the bulk ordered $\mathrm{Fe}_{3}$ Pt alloys of Refs. 10 and 11. Wiele et al. ${ }^{9-11}$ have observed that, with increasing $\mathrm{L}_{2}$ ordering, the $g(E)$ contributions of these medium-energy bands decrease relative to that of the dominant $\sim 30$ meV peak, ${ }^{50}$ and, moreover, that the $\sim 30 \mathrm{meV}$ peak shifts (by $\sim 1 \mathrm{meV}$ ) to higher energy. ${ }^{9-11}$ A similar blueshift is observed for our NCs [item (iv) above]. (b) In-plane projected $g(E)$; since our NRIXS experiment is performed at grazing incidence of the X-ray beam relative to the $\mathrm{SiO}_{2} / \mathrm{Si}(111)$ wafer (substrate), it is the in-plane projected PDOS of our NCs that is measured. Any structural anisotropy, induced, for instance, by mechanical stress between NC and substrate, could result in changes in the PDOS, where certain phonon modes can be enhanced or suppressed relative to the isotropic case. Since Wiele et al. ${ }^{9-11}$ used a polycrystalline bulk $\mathrm{Fe}_{3} \mathrm{Pt}$ sample in their NRIXS experiment, their measured $g(E)$ is the isotropic case. (c) Phonon conversion at the NC interface; it is known that the presence of interfaces may change the character of optical phonons from pure longitudinal optical (LO) or transverse optical (TO) to a mixture involving LO, TO, and interface modes. ${ }^{51}$ Since mixing results in larger dispersion, the PDOS in NCs can be modified.

It is worthwhile mentioning that $g(E)$ of our sample 2 (fcc $\left.{ }^{57} \mathrm{Fe}_{0.75} \mathrm{Pt}_{0.25}\right)$ presents some resemblances with data previ- ously measured by Tanaka et al. ${ }^{52}$ on fcc-Fe precipitates $(80$ $\mathrm{nm}$ in diameter) using NRIXS. In particular, a dominant 31 meV peak (LA phonons), relatively strong TA bands near $\sim 18$ and $\sim 23 \mathrm{meV}$, and a cutoff at $\sim 37 \mathrm{meV}$ was measured by Tanaka et al., ${ }^{52}$ but no feature near $\sim 7-9 \mathrm{meV}$ (typical for Fe-rich Fe-Pt alloys) was observed, contrary to the case of our fcc ${ }^{57} \mathrm{Fe}_{0.75} \mathrm{Pt}_{0.25} \mathrm{NCs}$, Fig. 4(b) (inset).

We would like to emphasize that for our ordered ${ }^{57} \mathrm{Fe}_{0.75} \mathrm{Pt}_{0.25}$ NCs [sample 2, Fig. 4(b)], we do not observe the low- and high-E enhancements of $g(E)$ that appear for the bcc ${ }^{57} \mathrm{Fe}_{0.8} \mathrm{Pt}_{0.2} \mathrm{NCs}$ in sample 1 [Fig. 4(a)]. As we discussed above, the low- and high-E enhancements of $g(E)$ is attributed to the specific core/shell structure of these NCs (bcc ${ }^{57} \mathrm{Fe}_{0.8} \mathrm{Pt}_{0.2}$ core and PtSi shell). For sample 2, due to strong Pt surface segregation, a rather thick PtSi shell exists, (as indicated by our XPS data), preventing low- and high-E enhancements of $g(E)$, as expected.

Several important thermodynamic quantities can be derived from the measured PDOS, ${ }^{32-36}$ such as the LambMössbauer (Debye-Waller) factor, kinetic energy, and the vibrational entropy and specific heat (all per atom). Table I displays the values obtained for the NCs in our samples 1-3, nanocrystalline $\mathrm{Fe},{ }^{45}$ fcc $\mathrm{Fe}$ precipitates in $\mathrm{Cu},{ }^{52}$ and bulk bcc $\mathrm{Fe}^{53}$ for comparison. These quantities, together with the measured partial DOS, should allow a good test of the Fe-Fe, Fe-Pt, and Pt-Pt pair potentials in theoretical work. Generally, according to Table I and independent of the structure, all values given for the NCs are smaller than for bulk bcc Fe, except the kinetic energy per atom, which appears enhanced. The values for bcc $\mathrm{Fe}_{0.8} \mathrm{Pt}_{0.2} \mathrm{NCs}$ are comparable to those of nanocrystalline $\mathrm{Fe}$.

\section{SUMMARY}

Summarizing, pronounced modifications (relative to the bulk) in the Fe-projected PDOS, $g(E)$, of isolated bcc ${ }^{57} \mathrm{Fe}_{0.8} \mathrm{Pt}_{0.2}$ and fcc ${ }^{57} \mathrm{Fe}_{0.75} \mathrm{Pt}_{0.25}$ (Invar type) $\mathrm{NCs}$ on a $\mathrm{SiO}_{2} / \mathrm{Si}(111)$ support have been measured by NRIXS. Segregation of $\mathrm{Pt}$ atoms to the NC surface was observed by XPS upon annealing and $\mathrm{Ar}^{+}$sputter etching, leading to core/shell structures with Fe-rich cluster cores and PtSi cluster surfaces. The enhancement of the low- and high-E regions of $g(E)$ observed for the bcc NCs is in qualitative agreement with theoretical predictions. By contrast, due to their different shell structure, no such enhancement was observed for the fcc Fe NCs, which show characteristic phonon features of 
bulk ordered $\mathrm{Fe}_{3} \mathrm{Pt}$ Invar alloys. Our observation of the Invar-typical [110] $\mathrm{TA}_{1}$ phonon mode in ${ }^{57} \mathrm{Fe}_{0.75} \mathrm{Pt}_{0.25} \mathrm{NCs}$ provides indirect evidence for the persistence of Invarrelated effects in NCs. The obtained modified PDOS will affect the thermal stability and thermodynamic properties of the NCs relative to bulk materials. Moreover, our work demonstrates the power of NRIXS for the nondestructive metallurgical phase analysis of alloy nanoclusters. ${ }^{54}$

\section{ACKNOWLEDGMENTS}

Discussions with Ralf Meyer (Sudbury), M. Gruner, and P. Entel (Duisburg-Essen) are greatly appreciated. This work was supported by NSF (Grants No. CAREER-DMR0448491 and No. DMR-0906562) and U.S. DOE (Grant No. DE-AC02-06CH11357). *roldan@ physics.ucf.edu

${ }^{1}$ B. Fultz, Prog. Mater. Sci. (to be published).

${ }^{2}$ N. A. Zarkevich, T. L. Tan, and D. D. Johnson, Phys. Rev. B 75, 104203 (2007).

${ }^{3}$ For a review see E. F. Wassermann, in Ferromagnetic Materials, edited by K. H. Buschow and E. P. Wohlfarth (North-Holland, Amsterdam, 1990), Vol. VI, p. 240ff.

${ }^{4}$ D. D. Johnson and W. A. Shelton, in The Invar Effect: A Centennial Symposium, edited by J. Wittenauer (The TMS Society, Philadelphia, 1997), p. 63.

${ }^{5}$ K. Tajima, Y. Endoh, Y. Ishikawa, and W. G. Stirling, Phys. Rev. Lett. 37, 519 (1976).

${ }^{6}$ Y. Noda and Y. Endoh, J. Phys. Soc. Jpn. 57, 4225 (1988).

${ }^{7}$ J. Kästner, J. Neuhaus, E. F. Wassermann, W. Petry, B. Hennion, and H. Bach, Eur. Phys. J. B 11, 75 (1999).

${ }^{8}$ J. Kästner, W. Petry, S. M. Shapiro, A. Zheludev, J. Neuhaus, Th. Roessel, E. F. Wassermann, and H. Bach, Eur. Phys. J. B 10, 641 (1999).

${ }^{9}$ N. Wiele, H. Franz, and W. Petry, Physica B (Amsterdam) 263264, 716 (1999).

${ }^{10}$ N. Wiele, H. Franz, T. Ansthalten, and W. Petry, Annual Report from the Advanced Photon Source, Report No. ANL-0015, 1999.

${ }^{11}$ N. Wiele, Ph.D. dissertation, Technische Universität München, Munich, 2001.

${ }^{12}$ P. Entel, E. Hoffmann, P. Mohn, K. Schwarz, and V. L. Moruzzi, Phys. Rev. B 47, 8706 (1993).

${ }^{13}$ M. Podgorny, Phys. Rev. B 43, 11300 (1991).

${ }^{14}$ M. Podgorny, Phys. Rev. B 46, 6293 (1992).

${ }^{15}$ W. A. Adeagbo, A. Zayak, and P. Entel, Phase Transitions 79, 853 (2006)

${ }^{16}$ J.-H. Gao, Q.-F. Zhan, W. He, D.-L. Sun, and Z.-H. Cheng, Appl. Phys. Lett. 86, 232506 (2005).

${ }^{17}$ J.-H. Gao, D.-L. Sun, Q.-F. Zhan, W. He, and Z.-H. Cheng, Phys. Rev. B 75, 064421 (2007).

${ }^{18}$ A. M. Glezer, E. N. Blinova, V. A. Pozdnyakov, and A. V. Shelyakov, J. Nanopart. Res. 5, 551 (2003).

${ }^{19}$ K. Kadau and P. Entel, Phase Transitions 75, 59 (2002).

${ }^{20}$ K. Kadau, M. Gruner, P. Entel, and M. Kreth, Phase Transitions 76, 355 (2003)

${ }^{21}$ L. Sandoval and H. M. Urbassek, Nano Lett. 9, 2290 (2009).

${ }^{22}$ R. Meyer, L. J. Lewis, S. Prakash, and P. Entel, Phys. Rev. B 68, 104303 (2003).

${ }^{23}$ A. Kara and T. Rahman, Surf. Sci. Rep. 56, 159 (2005).

${ }^{24}$ H. Yildirim, A. Kara, S. Durukanoglu, and T. S. Rahman, Surf. Sci. 600, 484 (2006).

${ }^{25}$ S. Durukanoglu, A. Kara, and T. S. Rahman, Phys. Rev. B 67,
235405 (2003)

${ }^{26}$ S. R. Calvo and P. B. Balbuena, Surf. Sci. 581, 213 (2005).

${ }^{27}$ H. Yildirim, A. Kara, and T. S. Rahman, J. Phys.: Condens. Matter 21, 084220 (2009).

${ }^{28}$ B. Roldan Cuenya, A. Naitabdi, J. R. Croy, W. Sturhahn, J. Y. Zhao, E. E. Alp, R. Meyer, D. Sudfeld, E. Schuster, and W. Keune, Phys. Rev. B 76, 195422 (2007).

${ }^{29}$ L. K. Ono, D. Sudfeld, and B. Roldan Cuenya, Surf. Sci. 600, 5041 (2006).

${ }^{30}$ A. Naitabdi, L. K. Ono, F. Behafarid, and B. Roldan Cuenya, J. Phys. Chem. C 113, 1433 (2009).

${ }^{31}$ J. R. Croy, S. Mostafa, L. Hickman, H. Heinrich, and B. Roldan Cuenya, Appl. Catal., A 350, 207 (2008).

${ }^{32}$ M. Seto, Y. Yoda, S. Kikuta, X. W. Zhang, and M. Ando, Phys. Rev. Lett. 74, 3828 (1995).

${ }^{33}$ W. Sturhahn, T. S. Toellner, E. E. Alp, X. Zhang, M. Ando, Y. Yoda, S. Kikuta, M. Seto, C. W. Kimball, and B. Dabrowski, Phys. Rev. Lett. 74, 3832 (1995).

${ }^{34}$ A. I. Chumakov, R. Rüffer, H. Grünsteudel, H. F. Grünsteudel, G. Grübel, J. Metge, O. Leupold, and H. A. Goodwin, Europhys. Lett. 30, 427 (1995).

${ }^{35}$ A. I. Chumakov and W. Sturhahn, Hyperfine Interact. 123-124, 781 (1999).

${ }^{36}$ W. Sturhahn, Hyperfine Interact. 125, 149 (2000).

${ }^{37}$ L. Zwell, G. R. Speich, and W. C. Leslie, Metall. Trans. 4, 1990 (1973).

${ }^{38}$ W. B. Pearson, Handbook of Lattice Spacings and Structures of Metal Alloys (Pergamon, Oxford, 1967), Vol. 2, p. 821.

${ }^{39}$ NIST X-ray Photoelectron Spectroscopy Database, Version 3.4 (Web Version) http://srdata.nist.gov/xps/index.htm

${ }^{40}$ A. Ethirajan, U. Wiedwald, H.-G. Boyen, B. Kern, L. Han, A. Klimmer, F. Weigl, G. Kästle, P. Ziemann, K. Fauth, J. Cai, R. J. Behm, A. Romanyuk, P. Oelhafen, P. Walther, J. Biskupek, and U. Kaiser, Adv. Mater. (Weinheim, Ger.) 19, 406 (2007).

${ }^{41}$ P. J. Grunthaner, F. J. Grunthaner, and A. Madhukar, J. Vac. Sci. Technol. 20, 680 (1982).

${ }^{42}$ C. Creemers and P. Deurinck, Surf. Interface Anal. 25, 177 (1997).

${ }^{43}$ U. B. Demirci, J. Power Sources 173, 11 (2007).

${ }^{44}$ Y. Ma and P. B. Balbuena, Surf. Sci. 602, 107 (2008).

${ }^{45}$ B. Fultz, C. C. Ahn, E. E. Alp, W. Sturhahn, and T. S. Toellner, Phys. Rev. Lett. 79, 937 (1997).

${ }^{46}$ B. Roldan Cuenya, W. Keune, R. Peters, E. Schuster, B. Sahoo, U. von Hörsten, W. Sturhahn, J. Zhao, T. S. Toellner, E. E. Alp, and S. D. Bader, Phys. Rev. B 77, 165410 (2008).

${ }^{47}$ R. Meyer, S. Prakash, and P. Entel, Phase Transitions 75, 51 (2002). 
${ }^{48}$ The high-energy oscillations above $\sim 40 \mathrm{meV}$ in Fig. 4(b) are believed to be an artifact due to the low count rate in that energy regime and the slightly higher background count rate for $E>$ $\sim 40 \mathrm{meV}$ as compared to $E<\sim-40 \mathrm{meV}$ in Fig. 3(b), combined with the mathematical Fourier-log procedure employed in the PHOENIX software used for data evaluation (Ref. 36).

${ }^{49}$ B. Fultz, T. A. Stephens, E. E. Alp, M. Y. Hu, J. P. Sutter, T. S. Toellner, and W. Sturhahn, Phys. Rev. B 61, 14517 (2000).

${ }^{50} \mathrm{In}$ a recent molecular-dynamics simulation of the PDOS of $\mathrm{Cu}_{3-\mathrm{x}} \mathrm{Au}_{\mathrm{x}}$ alloy NCs, a suppression of the low-E phonon bands relative to the high-E peak height and a blueshift of the high-E peak with increasing $\mathrm{L}_{2}$ ordering was predicted by $\mathrm{R}$. Meyer, Laurentian University, Sudbury, Canada (private communica- tion).

${ }^{51}$ B. Jusserand and M. Cardona, in Light Scattering in Solids V, Topics in Applied Physics, edited by M. Cardona and G. Güntherodt (Springer, Heidelberg, 1989), Vol. 66, p. 49.

${ }^{52}$ T. Tanaka, A. Tajima, R. Moriizumi, C. Oshima, Y. Tsunoda, M. Seto, S. Kitao, and T. Mitsui, J. Phys. Soc. Jpn. 74, 1762 (2005).

${ }^{53}$ G. Shen, W. Sturhahn, E. E. Alp, J. Zhao, T. S. Toellner, V. B. Prakapenka, Y. Meng, and H.-R. Mao, Phys. Chem. Miner. 31, 353 (2004).

${ }^{54}$ B. Roldan Cuenya, L. K. Ono, J. R. Croy, A. Naitabdi, H. Heinrich, J. Zhao, E. E. Alp, W. Sturhahn, and W. Keune, Appl. Phys. Lett. (to be published). 